\title{
O SIGILO DAS COMUNICAÇÕES E O USO DAS INTERCEPTAÇÕES \\ TELEFÔNICAS COMO MEIO DE PROVA NO PROCESSO PENAL: EM BUSCA DA PROTEÇÃO DA PRIVACIDADE
}

\author{
Marco Aurélio Rodrigues da Cunha e Cruz ${ }^{1}$ \\ Julivan Augusto Negrini ${ }^{2}$
}

Resumo: O objetivo deste artigo é examinar as dogmáticas relativas ao direito à privacidade $\mathrm{e}$ às funções do processo penal acusatório, para enfatizar o risco proporcionado pelo uso indiscriminado desta medida de urgência como fonte de prova no processo penal. Procede-se uma pesquisa teórica, de caráter qualitativo, com pesquisa jurisprudencial e bibliográfica. Emprega-se o método lógico-dedutivo e o referencial teórico está subsidiado nas doutrinas de Michael Foucault, Zigmunt Bauman, Luigi Ferrajoli e Stefano Rodotà.

Palavras-chave: Processo Penal, provas, interceptação telefônica, sigilo das comunicações e privacidade.

\section{SECRECY OF CORRESPONDENCE AND THE USE OF TELEPHONE INTERCEPTIONS AS A MEANS OF EVIDENCE IN THE CRIMINAL PROCEEDINGS: IN SEARCH OF PROTECTION OF PRIVACY}

\begin{abstract}
The purpose of this article is to examine the dogmatics related to the right to privacy and the functions of accusatory criminal instrument in order to draw the reader's attention to the risk posed by the indiscriminate use of this emergency measure as a source of evidence in criminal proceedings. A theoretical research of qualitative character is carried out with jurisprudential and bibliographical research. The hypothetical-deductive method is used and the theoretical reference is subsidized in the doctrines of Michael Foucault, Zigmunt Bauman, Luigi Ferrajoli and Stefano Rodotà.
\end{abstract}

Keywords: Criminal proceedings, evidence, telephone interception, secrecy of correspondence and privacy.

\section{INTRODUÇÃO}

Mesmo diante do avanço tecnológico da informática e do surgimento de novos sistemas de comunicações que se utilizam do fluxo de dados criptografados para fins de comunicações, o debate acerca do uso das interceptações telefônicas como meio de prova no

\footnotetext{
${ }^{1}$ Doutor em Direito Constitucional pela Universidad de Sevilla (título revalidado pela UFPE). Professor Titular do Mestrado em Direitos Fundamentais da UNOESC (PPGD UNOESC), Professor Pesquisador da Escola Superior Associada de Goiânia (ESUP) e da Faculdade Cambury de Goiânia. Membro do cadastro nacional de avaliadores (BASIS) de cursos de Direito do INEP/MEC. [ORCID ID http://orcid.org/0000-0002-9343-5358].

${ }^{2}$ Mestre em Direito pelo Programa de Pós-graduação Stricto sensu da UNOESC, campus de Chapecó - SC. Especialista em Direito Penal e Direito Processual Penal pela Faculdade Meridional - IMED. Advogado Criminalista e membro do corpo docente do curso de direito da UNOESC, campus de Chapecó - SC. [ORCID ID https://orcid.org/0000-0003-4706-4805].
}

Revista de Direito Penal, Processo Penal e Constituição | e-ISSN: 2526-0200 | Porto Alegre | v. 4 | n. 2 | p. $60-80$ | Jul/Dez. 2018 
Processo Penal ainda tem se mostrado atual e pertinente. A importância deste estudo se revela diante da intensificação da quebra do sigilo telefônico para fins de produção de prova em processos ou investigações de natureza criminal. Não são raras as situações em que a interceptação se constitui na principal (senão a única) prova de demonstração da culpa. Para aferir estas assertivas, segundo os relatórios do Conselho Nacional de Justiça (CNJ) divulgados no Sistema Nacional de Controle de Interceptações, desde janeiro de 2008 até novembro de 2018, 426.999 procedimentos criminais foram instaurados para fins de interceptações e 2.358.385 aparelhos telefônicos já foram alvo de monitoramento. A maior parte teve origem na Justiça Estadual, onde foram instaurados 402.006 procedimentos e 2.080.376 aparelhos foram monitorados. Além dos procedimentos relativos aos ramais telefônicos, também foram instaurados 41.488 procedimentos envolvendo interceptações em sistemas de informática, onde 95.548 endereços eletrônicos foram monitorados pelos órgãos de investigação $(\mathrm{CNJ}, 2018)^{3}$.

A justificativa, pois, da discussão deste tema se deve ao fato de que as comunicações telefônicas possuem natureza sigilosa, conforme assegurado pelo art. $5^{\circ}$, inciso XII, da Constituição Federal de 1988. Por outro lado, ao garantir o sigilo, a Constituição o faz por meio de uma previsão com reserva qualificada de lei, permitindo a sua restrição, desde que seja apenas para fins de investigação ou instrução criminal e mediante a observância de lei específica.

Porquanto, a quebra do sigilo telefônico é regulamentada pela lei $\mathrm{n}^{\circ} 9.296$, de 24 de julho de 1996, que disciplina os requisitos, a forma de realização e as hipóteses em que poderá ser autorizada a interceptação telefônica. Não obstante, o referido diploma legal tem sido objeto de inúmeras críticas por parte de alguns doutrinadores, os quais alertam para a imprecisão de seus termos e para a possibilidade do cometimento de abusos decorrentes de sua interpretação equivocada.

Por esta razão, o problema que se revela neste estudo diz respeito aos riscos do uso indiscriminado das interceptações telefônicas no processo penal frente a necessidade de

\footnotetext{
${ }^{3} \mathrm{O}$ sistema de controle de interceptações telefônicas foi criado no ano de 2008 pelo Conselho Nacional de Justiça e "[...] trata-se de sistema que concentra as informações das interceptações telefônicas que são impetradas no tribunal. Essa ferramenta possibilita a emissão de estatísticas que permitem aperfeiçoar e uniformizar o sistema de medidas cautelares sigilosas referentes às interceptações telefônicas, para constituir instrumento de prova em investigação criminal e em instrução processual penal, em todo o território nacional." (CNJ, 2018). Os relatórios quantitativos dos dados cadastrados no sistema podem ser obtidos junto ao endereço eletrônico http://www.cnj.jus.br/interceptacoes_tel/relatorio_quantitativos.php.
} 
proteção do direito à privacidade. Este meio de prova tem sido cada vez mais utilizado em procedimentos de natureza criminal, nem sempre de maneira plenamente justificada, o que coloca em risco concretização do direito à privacidade.

Movido por este embate, o presente artigo tem por objetivo estabelecer os principais critérios de conceituação da privacidade e das funções do processo penal acusatório, com o intuito de enfatizar o risco proporcionado pelo uso indiscriminado de medidas de urgência como fonte no Processo Penal. Para a concretização deste objetivo, será realizado um estudo teórico, de caráter qualitativo, por meio de uma pesquisa jurisprudencial e bibliográfica. O trabalho se valerá do método lógico-dedutivo, abordando os seguintes temas: a) a caracterização do processo penal no Estado Democrático de Direito, cujo objetivo é propiciar uma válida interpretação das finalidades do processo, segundo o art. $1^{\circ}$ da Constituição Federal (CF-88); b) o estudo do conceito de privacidade enquanto direito fundamental, onde serão analisadas algumas definições acerca do aludido direito; c) a abordagem sobre a insegurança como causa da mitigação da privacidade, momento em que se buscará compreender os efeitos da insegurança social no processo penal e, por fim; d) a análise dos limites do uso das interceptações telefônicas como forma de garantir a proteção da privacidade, ocasião em que serão apresentados os argumentos necessários para responder ao problema de pesquisa apresentado.

A pesquisa está subsidiada em obras bibliográficas que dissertam sobre os temas em estudo, especialmente nas doutrinas de Michael Foucaut (2002), Zigmunt Bauman (2013), Luigi Ferrajoli (2002) e Stefano Rodotà (2008). Obviamente não se pretende esgotar a discussão do tema, mesmo porque, trata-se de uma temática complexa e que refoge aos limites deste trabalho. De qualquer sorte, mostra-se pertinente o estudo, especialmente considerando o crescente aumento do uso das interceptações telefônicas e de outros meios restritivos como fonte de prova no processo penal.

\section{O PROCESSO PENAL NO ESTADO DEMOCRÁTICO DE DIREITO DA REPÚBLICA FEDERATIVA DO BRASIL (ART. 1 $^{\circ}$, CF-88)}

Inicialmente, é necessário tecer alguns comentários acerca das finalidades do Processo Penal no Estado Democrático de Direito e sobre a ordem constitucional dentro da qual ele está vinculado, pois é neste contexto que será inserida a interceptação telefônica, 
enquanto prova de um fato delituoso. Vale lembrar que o art. $1^{\circ}$ da $\mathrm{CF}-88^{4}$, dispõe que a República Federativa do Brasil se constitui em Estado Democrático de Direito, onde a efetividade das garantias individuais se apresenta como um elemento distintivo em relação a outras formas de organização do poder.

Por meio dessa leitura é possível perceber a presença de uma garantia limitadora do poder estatal, no sentido de que o poder conferido ao Estado, apesar de sua inevitável interferência na vida cotidiana das pessoas, deverá permanecer limitado à observância das

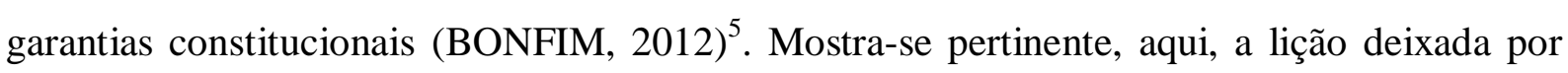
Bobbio (1997, p. 156), segundo a qual "somente o poder cria o direito" e "só o direito limita o poder".

Segundo James Goldschmidt, citado por Lopes Jr. (2016), o Processo Penal deve ser um segmento da política criminal instituída pela Constituição. Assim, diante de uma Carta autoritária, emanará um processo penal autoritário; por outro lado, diante de uma Constituição democrática, deverá emanar um Processo Penal democrático e harmonizado com as garantias individuais asseguradas no texto constitucional. Neste sentido, o art. $1^{\circ}$ da CF-88 foi interpretado pela Segunda Turma do Supremo Tribunal Federal no julgamento do Habeas Corpus $\mathrm{n}^{\circ} 98.237^{6}$ com o entendimento de que o controle jurisdicional da atividade persecutória do Estado é uma exigência inerente ao Estado Democrático de Direito. E que o sistema político pautado na democracia há de conter princípios que informem as relações entre o poder do Estado e os direitos do cidadão, pois:

Nesta perspectiva, há de se interpretar o processo penal com base em uma leitura constitucional, não podendo ele ser visto apenas como uma atividade legitimadora da pena ${ }^{7}$,

\footnotetext{
${ }^{4}$ Art. $1^{\circ}$ A República Federativa do Brasil, formada pela união indissolúvel dos Estados e Municípios e do Distrito Federal, constitui-se em Estado Democrático de Direito e tem como fundamentos: I - a soberania; II - a cidadania; III - a dignidade da pessoa humana; IV - os valores sociais do trabalho e da livre iniciativa; V - o pluralismo político.

${ }^{5}$ Na visão de Bonfim (2012, p. 41-43) "a presença do Estado enquanto entidade interfere cotidianamente na vida da sociedade, direcionando a sua atuação, impondo restrições ao que s indivíduos podem ou não fazer, reprimindo os infratores que afrontam bens ou interesses da sociedade ou do próprio Estado. Este, exercendo o poder, limita a liberdade individual, fazendo-o por meio do direito, que, neste sentido, funciona ele próprio como instrumento regulador da atividade estatal, já que esta não se pode dar sem controle, ou seja, de forma ilimitada."

${ }^{6}$ Não se pode tergiversar na defesa dos postulados do Estado Democrático de Direito e na sustentação da autoridade normativa da Constituição da República, eis que nada pode justificar o desprezo pelos princípios que regem, em nosso sistema político, as relações entre o poder do Estado e os direitos do cidadão". [HC 98.237, rel. min. Celso de Mello, j. 15-12-2009, 2 $2^{\mathrm{a}}$ T, DJE de 6-8-2010.]

${ }^{7}$ Neste sentido se posicionam Bonfim (2012, p. 47) para quem o Processo Penal representa "o ramo do direito público que se ocupa da forma e do modo (i.e.: o processo) pelos quais os órgãos estatais encarregados da administração da justiça concretizam a pretensão punitiva" e Capez $(2009$, p. 1), segundo o qual o Processo
}

Revista de Direito Penal, Processo Penal e Constituição | e-ISSN: 2526-0200 | Porto Alegre | v. 4 | n. 2 | p.

$60-80 \mid$ Jul/Dez. 2018 
mas também, como um instrumento de limitação do poder e da máxima eficácia dos direitos e garantias individuais (LOPES Jr., 2016). Ferrajoli (2002), em sua Teoria do Garantismo Penal, manifesta este entendimento por meio dos questionamentos "quando" e "como julgar", onde a presunção da inocência, a separação entre juiz e acusador, o ônus acusatório da prova e o direito de defesa, são elementos cruciais e indispensáveis para a estrutura do Processo Penal Democrático $^{8}$.

Em razão disso, Prado (2006, p. 16) menciona que “[...] a Constituição da República escolheu a estrutura democrática sobre a qual há que existir e se desenvolver o processo penal, forçado que está - pois modelo pré-constituição de 1988 - a adaptar-se e conformar-se a esse paradigma”. Isso significa que as regras infraconstitucionais devem encontrar seu fundamento na norma constitucional e qualquer inversão desta lógica ocasionará a invalidação da norma jurídica ordinária (QUEIROZ, 2001). Com efeito, as garantias individuais impostas pela Constituição Federal constituem um filtro pelo qual deve ser submetido o processo penal e, dessa forma, atividade persecutória somente passa a ter validade na medida em que suas regras estiverem construídas a partir da Constituição (LOPES Jr., 2016). Não basta ao Juiz aplicar a lei vigente, eis que necessário que se aplique a lei válida e esta deve ser entendida como aquela que encontra compatibilidade formal e material com a Constituição. (FERRAJOLI, 2002).

De fato, o maior desafio da atualidade é harmonizar o exercício do poder estatal com a existência de uma Constituição democrática, com todas as suas delimitações e com a liberdade própria de um Estado de Direito e Democrático (BARROSO, 2009). Não obstante, essa harmonização não tem sido uma tarefa fácil. No âmbito legislativo, é de se questionar a edição de leis penais de cunho meramente simbólico ou que visam combater o crime por meio do aumento abstrato das penas ${ }^{9}$. Ademais, urge apontar que não são raras a flexibilização das

Penal é um conjunto de princípios e normas que disciplinam a composição das lides penais, por meio da aplicação do Direito Penal objetivo.

${ }^{8}$ Para Ferrajoli (2002, p. 433) a observância destas regras é indispensável para a realização de um processo penal galgado em um sistema acusatório, o qual o autor chama de "submissão à jurisdição em sentido estrito", formada pelas teses "nullum iudicium sine accusatione, sine probatione, sine defensione".

9 O Direito Penal Simbólico se caracteriza como uma política criminal em que se verifica uma desnecessária inflação legislativa, onde são criadas figuras penais irrelevantes ou, então, o aumento desproporcional e injustificado das penas para os casos determinados (MASSOM, 2012, p. 11). Segundo Meliá (apud GÜNTHER, 2012, p. 79), "quando se usa em sentido crítico o conceito de Direito Penal Simbólico, quer-se, então, fazer referência a que determinados agentes políticos tão só perseguem o objetivo de dar a impressão tranquilizadora de um legislador atento e decidido, isto é, que predomina uma função latente sobre a manifesta, ou dito em uma 
garantias e a aplicação de medidas restritivas da liberdade baseadas na gravidade abstrata do fato ou na necessidade de manutenção da credibilidade nas instituições. ${ }^{10}$

Há que se compreender que o respeito às garantias individuais não representa o desprezo pela proteção social ou o favorecimento da impunidade. A persecutio criminis vocacionada para processo penal democrático se vincula pela observância das normas constitucionais que legitimam a aplicação da pena e fortalecem hierarquia extrema a ser dada aos direitos e garantias fundamentais protegidos pela Constituição. Uma atividade persecutória do Estado que contrarie esta ordem constitucional desnaturaliza a função democrática do processo penal e deslegitima os postulados a Constituição Federal.

\section{A PRIVACIDADE ENQUANTO DIREITO FUNDAMENTAL}

Ao buscar uma definição para a privacidade ${ }^{11}$, torna-se imperioso dizer que a Constituição Federal não faz menção a este termo, limitando-se a mencionar as expressões “vida privada" e "intimidade". Não obstante, os termos privacidade, intimidade e vida privada são expressões cujas definições geram muitas controvérsias. Alguns afirmam que cada um desses termos está a expressar um sentido diverso ${ }^{12}$. Outros mencionam que não há distinção entre estes termos ${ }^{13}$. Há, por fim, aqueles que entendem que a distinção não possui nenhuma consequência prática e, ainda, sequer seria recomendada, pois a definição de um conceito

nova formulação, que há uma discrepância entre os objetivos invocados pelo legislador - e os agentes políticos que conformam a maioria deste - e a 'agenda real' oculta sob aquelas declarações expressas."

10 Ao julgar o RHC 83.186/MG, o Min. Joel Ilan Paciornik, da Quinta Turma do Superior Tribunal de Justiça, manifestou seu entendimento no sentido de que a gravidade do delito é fundamento idôneo para sustentar a prisão preventiva do acusado em crime de tráfico de drogas (BRASL. Superior Tribunal de Justiça. Recurso em Habeas Corpus $\mathrm{n}^{\circ}$ 83.186/MG, julgado pela Quinta Turma, publicado em 01/08/2017. Disponível em: <https://ww2.stj.jus.br/processo/revista/inteiroteor/>. Acesso em: 23 jul. 2018). Da mesma forma, o Supremo Tribunal Federal tem se manifestado favorável a decretação da prisão preventiva nos casos em que houver a demonstração da gravidade do fato, conforme decisões proferidas nos HC $\mathrm{n}^{\circ} 140.089 / \mathrm{SP}$, publicado em 23/05/2017; $\mathrm{HC}^{\circ}{ }^{\circ} 134.900 / \mathrm{RS}$, publicado em 28/06/2017 e RHC 116.965, publicado em 13/08/2013, todos disponíveis em: <http://www.stf.jus.br/portal/jurisprudencia/>. Acesso em: 23 jul. 2018.

${ }^{11}$ O termo "privacidade" surgiu a partir da influência da doutrina na privacy de Warren e Brandeis (1890), a partir do artigo intitulado "The rigth of privacy", onde os autores, motivados por exageros contidos em publicações da imprensa de Boston sobre o matrimônio da filha do primeiro, concluíram que a através do direito à privacy seria possível inibir a interferência na vida privada: "A partir da análise dos precedentes, documentou-se o reconhecimento na common law de um direito geral à privacy, reconstruído por meio dos casos de violação de propriedade (property), violações da confiança (breach of confidence), violações do direito de autor (copyright) e também dos casos de difamação (defamation)".

${ }^{12}$ Nesse sentido, por exemplo, é o entendimento manifestado por Silva (2013); Diniz (2011); Morais (2014) e Mendes (2012).

${ }^{13}$ Assim entende Cernicchiaro e Costa Junior (1991); Doneda (2006); Araújo (1996); Caldas (1997); Vieira (2002) e Cretella Júnior (1989).

Revista de Direito Penal, Processo Penal e Constituição | e-ISSN: 2526-0200 | Porto Alegre | v. 4 | n. 2 | p.

$60-80 \mid$ Jul/Dez. 2018 
unitário e universal poderia ensejar a restrição ou ampliação injustificada do seu âmbito de proteção $^{14}$.

De qualquer sorte, como forma de sistematizar o estudo e evitar qualquer confusão conceitual, adotar-se-á, neste trabalho, a expressão privacidade, partindo-se do pressuposto de que é representativa da intimidade e da vida privada, consoante doutrina de Silva (2013), em que se insere a proteção do sigilo das comunicações telefônicas como um dos postulados para a observância daquele direito.

Não obstante, estabelecer um conceito de privacidade mostra-se uma tarefa complexa, pois os aspectos que a circundam variam conforme a época e a cultura de cada povo, o que dificulta a precisão de seu significado (MORI, 2000). Conceituar a privacidade, pois, exige a investigação das razões que fundam a necessidade de sua proteção. Há quem defenda que o termo privacidade origina-se do inglês privacy, que significa aquilo que é privado, próprio, individual, pessoal ${ }^{15}$. Atribuída aos direitos relacionados com a personalidade da pessoa humana, a noção de privacidade possui suas origens no século XIX, com o fortalecimento da classe burguesa e o exponencial crescimento do capitalismo, ocasião em que surge o desejo e a necessidade de se impor limites à publicidade de certos aspectos da vida das pessoas ${ }^{16}$. Assim, foi na sociedade moderna que seu conceito ganhou consistência e se firmou como direito fundamental e passou a ser positivado (MORI, 2000).

Em sua em sua concepção inicial, a privacidade possuía apenas conotação de direito negativo, eminentemente de defesa, pois gerava aos demais um dever de abstenção, de não ingerência. Ainda, identificava-se com a proteção da vida íntima e familiar do cidadão, dentro dos contornos de sua propriedade. "Do mesmo modo que o direito à propriedade permitia repelir o esbulho dos bens materiais, a privacidade permitia afastar a interferência alheia sobre a vida íntima de cada um.” (SCHREIBER, 2011, p. 129).

${ }^{14}$ É o entendimento de Leonardi (2011) e Dotti (1980).

${ }^{15}$ Para Costa Junior (2004, p. 36), o direito à privacidade representa um gênero do qual a intimidade é espécie. Isto porque, a privacidade está relacionada com os aspectos pessoais em geral, sejam de ordem pessoal ou profissional, enquanto a intimidade tem por escopo a proteção de informações pessoais, de foro íntimo e que o sujeito queira manter em segredo.

${ }^{16}$ Segundo Cunha e Cruz (2015, p. 64) "de fato, até o século XIX não se tem notícia de uma preocupação jurídica específica e teorizada da intimidade. $\mathrm{O}$ tratamento jurídico ao instituto se dava pela proteção à propriedade e ao direito contratual. Com a Revolução Industrial, com modificação da sociedade e a substituição gradativa de seus valores eminentemente agrários e de seus costumes mais simples por relações mais complexas, a partir do crescimento das cidades, do surgimento do consumo de massa e do desenvolvimento tecnológico, o debate sobre o direito à intimidade foi se emergindo. Exige-se, pois, um sistema de proteção mais congruente com as ameaças e lesões destes câmbios sociais, ampliando a aplicação do conceito de intimidade". 
Neste ínterim, a privacidade passa a ser compreendida como um poder jurídico conferido à pessoa humana de subtrair do conhecimento público e impedir a divulgação de certos aspectos de sua vida privada (SILVA, 2013). Representa, pois, um "fenômeno sóciopsíquico, em que os valores vigentes em cada época e lugar exercem influência significativa sobre o indivíduo, que em razão desses mesmos valores sente a necessidade de resguardar do conhecimento das outras pessoas aspectos particulares da sua vida”. (SILVA, 2003, p. 41). Para Cavalieri Filho (1995), por exemplo, a privacidade representa o direito de estar só ou de possuir liberdade para tomar decisões na esfera da intimidade, impedindo que certos aspectos da vida privada cheguem ao conhecimento público. E segundo Ferraz Junior (1992), a privacidade é um direito subjetivo que se manifesta por meio de uma estrutura entre o sujeito, o conteúdo e o objeto do direito. Neste sentido, o sujeito representaria o titular da privacidade, podendo ser qualquer pessoa; o conteúdo seria a faculdade da pessoa de exigir dos outros o respeito ao que lhe é próprio e particular; o objeto estaria sendo representada pelo bem a ser protegido.

Atualmente, pode-se dizer que o conceito da privacidade passou a ter novos contornos, sofrendo influxos na configuração da vida privada e indo muito além do simples direito de estar só. Segundo Rodotà $(2008$, p. 25) “a privacidade deve ser considerada também como o direito de manter o controle sobre suas próprias informações e determinar a maneira de construir sua própria esfera particular." Para responder ao questionamento sobre a "Sociedade da Classificação", Rodotà (2008) prioriza o contexto em que se constituem as relações intersubjetivas, entre pessoas e organizações, e entre as organizações. Admite que na maioria das relações mediadas na e pela Internet são produzidos os transactional data ou telecomunications-related personal informations (TRPI). Tais dados são constituídos pela relação contratual e permitem a aquisição automática de uma série de informações do consumidor ao fornecedor de serviços ou produtos. Tais dados (identificação, local, horário, forma de pagamento, modo de utilização de serviço) se configuram também informações sobre as escolhas e preferências.

Deste modo, a proteção da privacidade passa a impor deveres de caráter positivo e capazes de acompanhar esta dinâmica social. (SCHREIBER, 2011). Segundo Rodotà (2008) o conceito de privacidade passa de um direito de ser deixado em paz, a um direito de controle sobre as informações de cada um e de determinar como a esfera privada deve ser construída. De fato. Com a economia voltada para os dados (data driven economy), a informatização das 
relações, os reflexos econômicos e políticos decorrentes demandam do Direito uma repercussão sobre os problemas e conflitos desta incidência.

Doneda (2008) observa que a proteção de dados pessoais no Brasil pode ser prevista em disposições que convergem com a cláusula geral de proteção a pessoa humana. A proteção de dados pessoais é, portanto, uma garantia de caráter instrumental, derivada da tutela da privacidade, porém não limitada por esta, e que faz referência a um leque de garantias fundamentais que se encontram no ordenamento brasileiro (artigos $1^{\circ}$, II e III; $3^{\circ}$, III; $5^{\circ}$, X, XI, XII, LXXII, CF-88).

A perspectiva protetiva de dados pessoais já foi ressaltada por Leonardi (2011) ao categorizar em quatro os conceitos unitários de privacidade, para logo após defender um conceito plural. O referido autor invoca a postura de Westin entre os quatro primeiros conceitos que integram este último, pautada na razão de que o atributo básico do direito à privacidade era a capacidade de controle da circulação de informações e dados pessoais. Observa que as várias das tentativas em estabelecer um conceito unívoco de privacidade se sustentam no método tradicional da definição per genus et differentiam, que acolhe ou refuta as hipóteses conceituais conforme sua coerência, lógica e consistência. Denuncia que a problematização deste procedimento conduz a conceitos ora extremadamente restritivos, ora abusivamente abrangentes. Propõe, portanto, um conceito plural de privacidade, baseado em José Afonso da Silva (2013) e Stéfano Rodotà (2008).

Para Rodotà (2008, p. 109) há de se prevalecer uma concepção que se vocacione no "direito manter o controle sobre as próprias informações e de determinar as modalidades de construção da própria esfera privada. O objeto deste direito pode ser identificado no 'patrimônio informativo atual ou potencial' de um sujeito" (grifo no original). Sobre este conceito, lê-se que a informação exsurge como mediadora entre a vida privada e o livre desenvolvimento da personalidade.

Pelo exposto, percebe-se que a conceituação do direito à privacidade é uma tarefa dinâmica, que não pode ser apresentada de forma objetiva e universal. De qualquer sorte, o direito à privacidade possui natureza de direito fundamental, eis que faz parte da categoria dos direitos de personalidade e é essencial para livre desenvolvimento da personalidade. Apenas a título de exemplo, a Declaração Universal das Nações Unidas, de 1948, assegura a todos os 
cidadãos a proteção da vida privada ${ }^{17}$, com reflexos no art. 17 do Pacto Internacional de Direitos Civis e Políticos, internalizado pelo Decreto N. 592/1992 ${ }^{18}$. No Brasil, a proteção da privacidade passou a ser expressamente assegurada com a CF-88, em seu art. $5^{\circ}$, inciso X e, especificamente em relação à proteção do sigilo das comunicações telefônicas pelo art. $5^{\circ}$, inciso XII. ${ }^{19}$

\section{A EVOLUÇÃO TECNOLÓGICA E A SENSAÇÃO DE INSEGURANÇA COMO FONTE DE MITIGAÇÃO DO DIREITO À PRIVACIDADE}

É induvidoso que o avanço científico e tecnológico, e as inúmeras transformações no meio social, não poderiam deixar de dialogar com o crescente aumento dos índices de criminalidade. A sensação constante de insegurança, geradora de medo, teve como um dos resultados a criação de sistemas de vigilância que possam lhe trazem conforto perdido. (SILVA SANCHEZ, 2001). Todavia, a presença da tão desejada vigilância faz crescer ainda mais o receio do "inimigo", o medo do outro, aumentando ainda mais a sensação de insegurança e, por consequência, nos fazendo buscar ainda mais recursos de proteção, ainda que à custa de direitos básicos. (BAUMAN, 2013).

Com isso, a sociedade passa a exigir do Estado a adoção de medidas urgentes e eficazes no combate ao crime, ainda que mediante a restrição da sua liberdade e da sua privacidade $^{20}$. A problematização, portanto, reside em permitir o acesso a sua vida privada ou a restringir parte de sua liberdade, desde que se possa elevar a segurança em relação às práticas criminosas. Ocorre que tudo isso possui consequências obscuras e perigosas à

17 Art. XII - Ninguém será sujeito à interferência em sua vida privada, em sua família, em seu lar ou em sua correspondência, nem a ataque à sua honra e reputação. Todo ser humano tem direito à proteção da lei contra tais interferências ou ataques.

18 “Art. 17. 1. Ninguém poderá ser objetivo de ingerências arbitrárias ou ilegais em sua vida privada, em sua família, em seu domicílio ou em sua correspondência, nem de ofensas ilegais às suas honra e reputação. 2. Toda pessoa terá direito à proteção da lei contra essas ingerências ou ofensas".

19 “Art. $5^{\circ}$ Todos são iguais perante a lei, sem distinção de qualquer natureza, garantindo-se aos brasileiros e aos estrangeiros residentes no País a inviolabilidade do direito à vida, à liberdade, à igualdade, à segurança e à propriedade, nos termos seguintes: [...]

X - são invioláveis a intimidade, a vida privada, a honra e a imagem das pessoas, assegurado o direito a indenização pelo dano material ou moral decorrente de sua violação; [...]

XII - é inviolável o sigilo da correspondência e das comunicações telegráficas, de dados e das comunicações telefônicas, salvo, no último caso, por ordem judicial, nas hipóteses e na forma que a lei estabelecer para fins de investigação criminal ou instrução processual penal;"

${ }^{20}$ Baumer (apud Gauer 2004, p. IX), argumenta que a descontrolada aceleração do tempo produzida pelo ser humano em seu desenvolvimento, embora seja excitante, faz com que permaneçamos presos a um "presencialismo" excessivo, onde a demora é tida como um sacrifício insuportável.

Revista de Direito Penal, Processo Penal e Constituição | e-ISSN: 2526-0200 | Porto Alegre | v. 4 | n. 2 | p.

$60-80$ | Jul/Dez. 2018 
efetivação do direito à privacidade, pois a busca pela segurança tende a limitar a liberdade, invadir a intimidade e intensificar a ingerência do poder estatal. A permissão de que o Estado possa se valer se medidas excepcionais sob a justificativa de solucionar um problema, só faz aumentar o poder e o controle social, ao passo que limita o exercício das liberdades.

Nada obstante, a dúvida gravita sobre o fato do Estado brasileiro ser capaz de gerir as medidas de segurança existentes como fez no passado ou de criar novos mecanismos de prevenção. Neste sentido, é notória a utilização de aparatos emergenciais de combate ao crime que não solucionam os problemas estruturais de sua sociedade, mas, em regra, acabam restringindo o exercício de direitos fundamentais, sob a justificativa de proporcionar à sociedade a segurança jurídica necessária para o convívio social.

É por esta razão que André Copetti (2002, p. 71) já entendeu que "assistimos a uma crise da positividade do Direito Penal que cada vez mais afasta nosso modelo estatal do standard do Estado Democrático de Direito, levando-nos em direção a um Estado arbitrário.” Em resumo, é possível constatar que o crescimento científico e tecnológico, necessário para o desenvolvimento econômico e do bem-estar material, desencadeou, por consequência, o surgimento de riscos de grandes dimensões, cujo potencial de perigo não se pode medir, quantificar ou antever. Neste contexto, "estamos assistindo a uma progressiva extensão das formas de controle social, motivadas, sobretudo por razões de segurança. A vigilância passa de excepcional a quotidiana, das classes 'perigosas' à generalidade das pessoas." (RODOTÀ, 2008, p. 238).

Em paráfrase do antigo modelo pan-óptico ${ }^{21}$ apresentado por Foucault (2002), vivese, hoje, sob a sensação de vigilância permanente. A adoção de medidas restritivas de urgência, apesar de revestidas de caráter excepcional, tem sido cada vez mais cotidiana em processos de natureza criminal. Motivados pela necessidade de solucionar os problemas da

${ }^{21}$ O pan-óptico, que significa "o lugar de onde tudo se vê”, que se constituía, na sua época, num modelo arquitetônico criado para prisões, que permitia a vigilância constante e o controle dos presos por parte do inspetor, que poderia se movimentar de forma livre e sem ser visto, enquanto os presos permaneciam imóveis e tinham de permanecer assim o tempo todo, pois não sabiam de onde estavam sendo vigiados. (BAUMAN, 2013, p. 18/19). Não obstante, Foucault (2002, p. 170) refere que o modelo pan-óptico vai muito além da mera vigilância das prisões, mas serve, também, "para cuidar dos doentes, instruir os escolares, guardar os loucos, fiscalizar os operários, fazer trabalhar os mendigos e ociosos. É um tipo de implementação dos corpos no espaço, de distribuição dos indivíduos em relação mútua, de organização hierárquica, de disposição dos centros e dos canais de poder, de definição de seus instrumentos e de modos de intervenção, que se podem utilizar nos hospitais, nas oficinas, nas escolas, nas prisões."

Revista de Direito Penal, Processo Penal e Constituição | e-ISSN: 2526-0200 | Porto Alegre | v. 4 | n. 2 | p.

$60-80$ | Jul/Dez. 2018 
persecução penal, o Judiciário tem sido cada vez mais conivente com o desrespeito às garantias e direitos fundamentais da pessoa humana.

Percebe-se, que o pan-óptico trata-se, na sua essência, de um instrumento de exercício do poder, que pode ser utilizado em qualquer segmento e por qualquer instituição, com o propósito de estabelecer a vigilância, não como garantia do vigiando, mas sim, como instrumento de disciplina que recai sobre este. Isso inverte a lógica do espetáculo, onde muitos observavam poucos, para uma lógica do castigo, onde poucos, ou apenas um, observava a todos, que se sentem sempre vigiados, pois nunca sabem quem (e se) os observa.

Entretanto, embora a teoria de Foucault seja necessária para a compreensão da vigilância e de seus efeitos, não se pode dissociar o contexto da Internet e da informação, onde além da disciplina, o controle social e o espetáculo também são características essenciais. Não se trata mais de um local onde muitos são observados por poucos, senão o contrário. É inevitável o papel e a inserção das mídias sociais, nas quais as pessoas permitem serem observadas por muitos, principalmente em sua intimidade, propiciando um significativo aumento das formas de vigilância e controle social. Este é o argumento de Bauman em Vigilância Líquida (2013), em que defende pós-panoptismo baseado no processamento de dados e mediado por informações dentro do contexto das tecnologias de comunicação. Permitem uma nova transparência, voltada para o monitoramento, para o controle, para a observação, para a classificação, para a checagem dos usuários e "venda" de dados pessoais; para estabelecer uma servidão do tipo "faça você mesmo".

A segurança passou a ser exercida por meio da vigilância permanente, na tentativa de monitorar o que vai acontecer pelo emprego de técnicas digitais e raciocínio estatístico. Acontece aqui o que o próprio Foucault (2002) chama de criação de corpos dóceis. A disciplina imposta aos cidadãos nos séculos XVII e XVIII transformou-se em uma fórmula de dominação, por meio da imposição de regras que permitem o controle minucioso das atividades sociais, sujeitando todos às regras que impõem uma condição de docilidade e aceitação, que os tornam mais obedientes e úteis. É o que o referido autor chama de "mecânica do poder". Com efeito, no Brasil, tem se constatado que uma das formas mais corriqueiras de violação da privacidade se dá por meio da quebra da violação do sigilo de correspondências e/ou comunicações ${ }^{22}$. Ainda que autorizado judicialmente como meio de

${ }^{22}$ Cita-se, como exemplo, a divulgação das conversas telefônicas entre os ex Presidentes Luiz Inácio Lula da Silva e Dilma Rousseff, nos autos do processo $\mathrm{n}^{\circ}$ 5006205-98.2016.4.04.7000/PR, onde o Juiz Sergio Moro, da 13 ${ }^{\mathrm{a}}$

Revista de Direito Penal, Processo Penal e Constituição | e-ISSN: 2526-0200 | Porto Alegre | v. 4 | n. 2 | p. $60-80$ | Jul/Dez. 2018 
garantir a segurança e a conveniência de uma investigação, o seu uso desmedido coloca em risco o âmbito de proteção do direito fundamental previsto no inciso XII, CF-88.

Por isso, se faz necessário repensar a atual realidade da sociedade da vigilância na qual somos inseridos, por meio do estabelecimento de regras e princípios que condicionem a atuação estatal e limitem a sua intervenção demasiada na vida privada de seus cidadãos, para que se possa conciliar a ideia de vigilância e respeito à privacidade da pessoa humana.

\section{O PROCESSO PENAL E A INTERCEPTAÇÃO TELEFÔNICA: ANALISANDO OS LIMITES DE SUA ACEITAÇÃO COMO PROVA}

Este texto defende que o Processo Penal há de ser concebido como um instrumento necessário para legitimar a atuação estatal no exercício do poder de punir (LOPES Jr., 2016). Neste contexto, a prova penal assume um papel determinante, uma vez que o reconhecimento da culpa é pressuposto da aplicação da pena. A prova, por sua vez, funciona como uma atividade retrospectiva, que visa proporcionar ao judiciário o conhecimento dos fatos (cognição) e formar seu convencimento (persuasão). Neste caminho, é inegável que a eleição, dentre as possibilidades possíveis do processo, deve ser aquela mais convincente e "esse eleger também se expressa na valoração da prova (crença) e na própria axiologia, incluindo a carga ideológica que faz da norma (penal ou processual penal) aplicável ao caso". (LOPES Jr., 2014. P. 552).

Assim, devido a sua importância para o processo, a prova penal deve observar algumas formalidades indispensáveis para a sua validade. No que se refere às interceptações telefônicas, objeto deste escrito, algumas considerações merecem destaque. As regras legais que regulamentam a quebra do sigilo das comunicações telefônicas do inciso XII, CF-88, estão disciplinadas na lei $n^{\circ}$ 9.296/96. Entretanto, o debate sobre a amplitude da restrição ao sigilo das comunicações telefônicas tem sido constante, pois algumas incongruências tornam difícil a compreensão destes limites.

Observa-se que o constituinte optou por possibilitar a quebra do sigilo das comunicações telefônicas apenas nos casos definidos em lei. É aí que se constata o primeiro

Vara Federal de Curitiba, autorizou a divulgação dos diálogos, justificando sua decisão no interesse público. Posteriormente a decisão de primeira instância foi reformada pelo Supremo Tribunal Federal que considerou ilegal a divulgação quando do julgamento da Medida Cautelar de Reclamação ${ }^{\circ}$ 23.457/PR, em que foi relator o Min. Teori Zavascki.

Revista de Direito Penal, Processo Penal e Constituição | e-ISSN: 2526-0200 | Porto Alegre | v. 4 | n. 2 | p.

60 - 80 | Jul/Dez. 2018 
problema. A lei n 9.296/96 disciplina a realização da interceptação telefônica ${ }^{23}$, entretanto, não menciona a possibilidade da gravação realizada por um dos interlocutores, sem o consentimento dos demais, ou até mesmo por terceiro, ainda que com o consentimento de um dos interlocutores ${ }^{24}$. Por essa razão, em observância ao princípio da legalidade, estas últimas não poderiam ser realizadas, ainda que judicialmente autorizadas, eis que as referidas formas não se encontram disciplinas em lei ${ }^{25}$. (GRECO FILHO, 2008).

Outra interrogação importante envolve a alegada inconstitucionalidade do parágrafo único, do art. $1^{\circ}$, da Lei $9.296 / 96^{26}$. Ao analisar o texto constitucional, percebe-se que o constituinte autorizou apenas a quebra do sigilo das comunicações telefônicas, não fazendo nenhum referencia à possibilidade da medida restritiva ser estendida às interceptações de dados informáticos ou telemáticos ${ }^{27}$. Seguindo este entendimento, o mencionado parágrafo seria inconstitucional. (GRECO FILHO, 2008).

Ainda, é necessário analisar os limites da autorização da quebra do sigilo das comunicações telefônica, com a leitura do art. $2^{\circ}$ da lei em estudo. ${ }^{28}$ Percebe-se que o legislador subverteu a lógica da exceção que estava a disciplinar e trouxe de forma expressa as hipóteses em que a interceptação não é autorizada. Esta subversão representa uma incoerência técnica legislativa, pois se a quebra do sigilo é a exceção (e não há dúvidas disso), deveria o legislador limitar as hipóteses em que a quebra do sigilo é possível.

${ }^{23}$ Para Rangel (1999) a interceptação telefônica refere-se a "captação feira por terceira pessoa de comunicação entre dois (ou mais) interlocutores, sem o conhecimento de qualquer deles". Ainda, Greco Filho (2015, p. 22) afirma que "a interceptação, em sentido estrito, é realizada por alguém sem autorização de qualquer dos interlocutores para a escuta e eventual gravação de conversa, e com o desconhecimento deles".

${ }^{24}$ A gravação ambiental de conversa informal do acusado sem o seu conhecimento possui natureza ilícita, pois ofende o direito ao silêncio. Neste sentido foi a decisão proferida pelo Superior Tribunal de Justiça no julgamento do $\mathrm{HC} \mathrm{n}^{\circ}$ 80.949/RJ, de relatoria do Min. Sepúlveda Pertence.

${ }^{25}$ Em sentido contrário, o Min. Jorge Scartezzini, do Superior Tribunal De Justiça no julgamento do RO em HC n ${ }^{\circ}$ 9.735/SP.

${ }^{26}$ Art. $1^{\circ}$ A interceptação de comunicações telefônicas, de qualquer natureza, para prova em investigação criminal e em instrução processual penal, observará o disposto nesta Lei e dependerá de ordem do juiz competente da ação principal, sob segredo de justiça.

Parágrafo único. O disposto nesta Lei aplica-se à interceptação do fluxo de comunicações em sistemas de informática e telemática.

${ }^{27}$ Há, no entendo, quem discorde desta posição, como é o caso do doutrinador Paulo Rangel (1999), para quem o constituinte permitiu a quebra do sigilo de dados, sejam das comunicações telefônicas, sejam de outras formas de comunicação.

${ }^{28}$ Art. $2^{\circ}$ Não será admitida a interceptação de comunicações telefônicas quando ocorrer qualquer das seguintes hipóteses:

I - não houver indícios razoáveis da autoria ou participação em infração penal;

II - a prova puder ser feita por outros meios disponíveis;

III - o fato investigado constituir infração penal punida, no máximo, com pena de detenção.

Revista de Direito Penal, Processo Penal e Constituição | e-ISSN: 2526-0200 | Porto Alegre | v. 4 | n. 2 | p.

$60-80 \mid$ Jul/Dez. 2018 
De qualquer forma, ao autorizar a quebra do sigilo, o constituinte não deu poderes ilimitados aos legisladores ordinários ou ao julgador para determinarem a restrição do direito fundamental do inciso XII do artigo $5^{\circ}$ (CF-88) da maneira que lhes aprouver. Deve ser respeitado o seu âmbito de proteção, definido pelo suporte fático da norma constitucional. Neste contexto, a interceptação telefônica somente pode ser autorizada quando o objeto da investigação se tratar de crime punido com pena de reclusão (inciso III) e investigação já conte com indícios razoáveis de autoria ou participação (inciso I), não podendo a prova ser obtida por outro meio igualmente disponível (inciso II). Todavia, apesar da existência destes, percebe-se que os limites legais são vagos e imprecisos, especialmente no que se refere aos incisos I e II, o que pode gerar controvérsias no que se refere a sua interpretação. Afinal, o que se entende por "razoáveis indícios" de autoria ou participação? Ainda, considerando a existência de inúmeros meios de produção de prova, como se poderia constatar a imprescindibilidade da interceptação diante da inexistência de "outros meios" disponíveis para a produção da prova?

Merece igualmente destaque a previsão do inciso III, que possibilita a realização da interceptação em todos os crimes cuja lei comine pena de reclusão. Questiona-se: seria proporcional admitir a restrição de um direito fundamental para buscar a punição em crimes de pequena gravidade, cujo bem jurídico tutelado pela lei penal possui menor carga valorativa, apenas para saciar o clamor incriminatório de que foi tomado o legislador nos últimos anos? Logicamente, parece que a resposta a esse questionamento é negativa. Ora, o legislador não quis, por certo, permitir a interceptação em crimes de menor potencial ofensivo ou, por exemplo, em crimes de furto (e semelhantes) em que se permite a suspensão condicional do processo, nos termos do art. 89 da Lei 9.009/95 (RANGEL, 1999). Todavia, não há previsão expressa no sentido de limitar a utilização das interceptações apenas para crimes mais graves, o que faz ser possível a banalização do instituto.

Outra questão acerca da lei $\mathrm{n}^{\circ}$ 9.296/96 diz respeito do prazo da interceptação telefônica. A lei aponta que o prazo não pode exceder o limite máximo de quinze dias, podendo ser renovável por igual tempo. Entretanto, não há uma previsão quanto aos limites de 
prorrogações deste prazo, o que ocasiona, por vezes, a renovação reinterada da medida por tempo demasiadamente prolongado, reverberando a vigilância incessante. ${ }^{29}$

Indaga-se, ainda, desde a entrada em vigor da lei 9.296/96, a legitimidade conferida ao Juiz para conceder de ofício a realização da interceptação telefônica ou telemática, segundo dispõe o art. $3^{\circ 30}$. O tema é objeto de discussão na ADI $n^{\circ} 4112$, proposta no ano de 2008 pelo Partido Trabalhista Brasileiro - PTB e ainda encontra-se pendente de julgamento. No referido processo, a Procuradoria Geral da República proferiu parecer manifestando a impossibilidade da atuação de ofício apenas na fase de investigação. Este é o entendimento manifestado por Paulo Rangel (1999, p. 6):

Assim, devemos ressaltar que o Juiz não deve conceder de ofício a medida cautelar preparatória, pois esta deverá ser requerida pelo Ministério Público (dominus litis) ou mediante representação da autoridade policial, pois pelo sistema acusatório, adotado entre nós, o juiz foi afastado da persecução penal. Porém, nada obsta, que a medida cautelar incidental (adotada no curso do processo) possa ser deferida pelo juiz de ofício, em nome do princípio da verdade real e de acordo com o sistema do livre convencimento.

Deve-se mencionar que uma das principais características de um sistema processual acusatório é a separação das funções entre juiz e acusador, fazendo com que a atividade probatória passe a ser exclusivamente das partes. O juiz deve se manter distante da atividade probatória, para que não venha a se contaminar por ela. Registra-se, novamente, que as provas são consideradas como atrativos psíquicos destinados a formar o convencimento do julgador. Assim, no momento em que este interfere na produção da prova, gerindo a sua produção, corre-se o risco de decidir antes e, depois, produzir a prova necessária para justificar sua convicção. (COUTINHO apud LOPES Jr., 2014). Por essa razão, valendo-se da assertiva de Luiz Flavio Gomes (2007, p. 201/202):

É inconstitucional a interceptação telefônica 'de ofício', em consequência, porque vulnera o modelo acusatório de processo, processo de partes, instituído pela Constituição de 1988, quando considera os ofícios da acusação e da defesa como funções essenciais da jurisdição, atribuindo esta aos juízes, que têm competência para processar e julgar, mas não para investigar, principalmente no âmbito extraprocessual.


reconhecida a repercussão geral para discutir sobre a constitucionalidade da prorrogação do prazo de duração da interceptação telefônica.

30 Art. $3^{\circ} \mathrm{A}$ interceptação das comunicações telefônicas poderá ser determinada pelo juiz, de ofício ou a requerimento: I - da autoridade policial, na investigação criminal; II - do representante do Ministério Público, na investigação criminal e na instrução processual penal. 
A função do Judiciário não é outra a não ser zelar pela proteção dos direitos e garantias fundamentais previstas em nossa Constituição. O Processo Penal brasileiro, pois, deve-se forjar em um sistema acusatório, com a separação de funções, onde o Juiz precisa se manter distante da atividade das partes, para que não comprometa a sua imparcialidade. É por isso que em um sistema penal acusatório, a acusação possui o ônus da prova e deverá fazê-lo de maneira formal, elaborada por termos unívocos e precisos e alicerçada em elementos mínimos de culpabilidade. Do outro lado, a defesa tem o direito do contraditório. O Juiz deve ser o espectador da prova, necessária para a formação da sua convicção:

De todos os elementos constitutivos do modelo teórico acusatório, o mais
importante, por ser estrutural e logicamente pressuposto de todos os outros,
indubitavelmente e a separação entre juiz e acusação. Essa separação, exigida por
nosso axioma nullum iudicium, sine accuscitione, forma a primeira das garantias
orgânicas estipuladas em nosso modelo teórico $S G$. Ela comporta não só a
diferenciação entre os sujeitos que desenvolvem funções judicantes e os que
desenvolvem funções de postulação e o consequente papel de espectadores passivos
e desinteressados reservado aos primeiros em virtude da proibição ne procedat iudex
ex offtcio, mas também, e sobretudo, o papel de parte - em posição de paridade com
a defesa - consignado ao órgão da acusação e a consequente ausência de qualquer
poder sobre a pessoa do imputado. (FERRAJOLI, 2002, p. 454/455).

Por esta razão, dentro de um sistema puramente acusatório, o Juiz não deve ser o gestor da prova. Esses são alguns dos motivos pelos quais caberá ao judiciário ter cautela na utilização da interceptação telefônica em procedimentos de natureza criminal, pois sendo esta uma exceção que restringe o direito fundamental do sigilo das comunicações telefônicas, somente deverá ser aceita dentro da sua estrita necessidade.

Como bem ilustra Ferrajoli (2002, P. 482) “A história das penas é uma história de horrores. A história dos julgamentos é uma história de erros." Cabe ao Estado, pois, minimizar a reação social frente ao delito, e não substituir a sociedade na busca da vingança. Em um regime democrático, o processo penal em deve ser o caminho para a punição dos culpados, mas sem se descuidar da proteção dos presumivelmente inocentes, e todos o são, pela dicção do texto constitucional, até o trânsito em julgado da decisão condenatória (inc. LVII, art. $5^{\circ}$ CF-88).

\section{CONSIDERAÇÕES FINAIS}

Os relatórios do Conselho Nacional de Justiça (CNJ) divulgados no Sistema Nacional de Controle de Interceptações, desde 2008 até 2018 demonstram o crescimento da 
vigilância constante de sistemas de captação de som e imagem, que permitem a coleta e processamento de informações pessoais. Dentro deste cenário, o que se mostra mais preocupante é a adoção de medidas restritivas de urgência que têm sido adotadas no processo penal por parte dos órgãos da persecução penal. Estas interceptações podem proporcionar uma grande interrogação sobre as hipóteses de violação de direitos e garantias fundamentais e colocar em risco o desenvolvimento do Estado Democrático.

Por essa razão que o presente estudo teve por escopo despertar a atenção para a necessidade de encontrar soluções factíveis para resolver certos problemas causados pelo uso das interceptações telefônicas, na tentativa de conciliar a sua utilização como meio de prova no Processo Penal sem restringir direitos visceralmente relacionados à privacidade, dentre os quais está o sigilo das comunicações telefônicas do inciso XII, do art. $5^{\circ}$, CF-88. Por meio do estudo realizado, algumas conclusões podem ser extraídas:

(i) A primeira, o Processo Penal exerce a função de instrumento limitador da liberdade, legitimando a aplicação da pena, mas também representa um instrumento limitador do poder estatal. Por isso, é necessário que regras inerentes ao Processo Penal sejam interpretadas conforme os ditames da Constituição. Assim, os direitos relacionados à privacidade, como é o caso do sigilo das comunicações telefônicas, deve ser observado, limitando a sua violação apenas quando autorizada por lei.

(ii) A segunda, o uso de recursos tecnológicos pelo Poder Judiciário tem intensificado a sua ingerência por meio do aumento da quebra do sigilo das comunicações telefônicas, o que dá azo a ofensas ao direito à privacidade representado no do inciso XII, do art. $5^{\circ}, \mathrm{CF}-88$, especialmente quando autoriza a interceptação telefônica de ofício ou quando renova a sua prorrogação de forma consecutiva, e por diversas vezes, quando não observa o sigilo da medida, divulgando o conteúdo das conversas interceptadas, entre outros.

(iii) A terceira, a Lei ${ }^{\circ}$ 9.296/96 ultrapassa os limites impostos pela reserva de lei da Constituição, autorizando a interceptação do fluxo de dados telemáticos, o que pode suscitar a sua inconstitucionalidade material neste ponto. Há imprecisão na sua fundamentação normativa, o que contribui para uma interpretação ambígua por parte do julgador, contribuindo para a ofensa à privacidade.

(iv) A quarta e derradeira, os excessos em muitos dos casos submetidos à apreciação do poder judiciário podem estar legitimados pela sensação de insegurança e a sua reação: a vigilância. Os recursos tecnológicos, neste sentido, são utilizados para fins de obtenção de 
provas, sem se preocupar com questões de sua adequação legal e constitucional relacionados à privacidade.

Não há como negar o fato de que o Estado tem o dever de criar mecanismos de proteção social com o fim de proporcionar a todos a devida segurança. Entretanto, se utilizar do processo penal como único subterfúgio para a realização deste fim não parece uma medida validamente democrática. O processo penal possui a função de servir como caminho para a aplicação da pena, sem que se desprezem as premissas democráticas do art. $1^{\circ}$ da CF-88, dispõe que a República Federativa do Brasil se constitui em Estado Democrático de Direito. Desta leitura democrática do processo penal deflui que o Estado tem o dever de zelar pelo respeito aos direitos e garantias fundamentais do acusado e refutar toda e qualquer medida que venha a transgredi-los ou desprezá-los, especialmente no que diz respeito à produção da prova por quebra do sigilo das comunicações telefônicas.

\section{REFERÊNCIAS}

ARAÚJO, Luiz Alberto David. A proteção constitucional da própria imagem. Belo Horizonte: Del Rey,1996.

BARROSO, Luís Roberto. Curso de Direito Constitucional Contemporâneo: os conceitos fundamentais e a construção do novo modelo. São Paulo: Saraiva, 2009.

BAUMAN, Zygmunt. Vigilância líquida: diálogos com David Lyon e Zygmunt Bauman. Rio de Janeiro: Zahar, 2013.

BOBBIO, Norberto. O futuro da democracia: uma defesa das regras do jogo. 6. ed. São Paulo: Paz e Terra, 1997.

BONFIM, Edilson Mougenot. Curso de processo penal. 7. ed. São Paulo: Saraiva, 2012.

BRASIL. Constituição. República Federativa do Brasil. Brasília, DF: Senado Federal, 1988. Disponível em: < http://www.planalto.gov.br/ccivil_03/constituicao/ constituicaocompilado.htm> Acesso em: 21 jul. 2016.

BRASIL. Lei n. 9.296, de 24 de julho de 1996. Regulamenta o inciso XII, parte final, do art. $5^{\circ}$ da Constituição Federal. Diário Oficial da União, Brasília, DF, 25 jul. 1994. Disponível em: < http://www.planalto.gov.br/ccivil_03/Leis/19296.htm>. Acesso em: 20 ago. 2016.

BRASIL. Supremo Tribunal Federal. A Constituição e o Supremo. 5. ed. atual. Até a EC 90/2015. Brasília: STF, Secretaria de Documentação, 2016.

CAPEZ, Fernando. Curso de processo penal. 16. ed. São Paulo: Saraiva, 2009. 
CAVALIERI FIHO, Sérgio. Programa de Responsabilidade Civil. Malheiros: São Paulo, 1996.

COPETTI, André. Direito Penal e Estado Democrático de Direito. Porto Alegra: Livraria do Advogado, 2000.

COSTA JÚNIOR, Paulo José da. O direito de estar só: tutela penal da intimidade. São Paulo: Siciliano Jurídico, 2004.

CONSELHO NACIONAL DE JUSTICA. Sistema Nacional de Controle de Interceptações Telefônicas, 2017. Disponível em: <http://www.cnj.jus.br/sistemas/interceptacoestelefonicas>. Acesso em: 03 abr. 2018.

CUNHA E CRUZ, Marco Aurélio Rodrigues. A configuração constitucional do direito à própria imagem. Editora Unoesc: Joaçaba, 2015.

DINIZ, Maria Helena. Curso de Direito Civil Brasileiro: Teoria Geral do Direito Civil. 28. ed. São Paulo: Saraiva, 2011.

DONEDA, Danilo. Da privacidade à proteção dos dados pessoais. Rio de Janeiro: Renovar, 2006.

DONEDA, Danilo. Iguais mas separados: o Habeas data no ordenamento brasileiro e a proteção de dados pessoais. Cadernos da Escola de Direito e Relações Internacionais, n. 9, p. 14-33, 2008.

DOTTI, René Ariel. A liberdade e o direito à intimidade. Senado Federal, Revista de informação legislativa, Brasília: Senado Federal, ano 17, n. 66, 1980.

FERRAJOLI, Luigi. Direito e razão: teoria do garantismo penal. São Paulo: Editora Revista dos Tribunais, 2002.

FERRAZ JUNIOR, Tércio Sampaio. Sigilo de dados: $O$ direito à privacidade e os limites à função fiscalizadora do Estado. São Paulo: Editora Revista dos Tribunais, 1992.

FOUCAULT, Michel. Vigiar e Punir. Rio de Janeiro: Editora Vozes, 2002.

GRECO FILHO, Vicente. Interceptação telefônica. 2. ed. São Paulo: Saraiva, 2005.

GAUER, Ruth M. Chittó (org.). A Qualidade do Tempo: Para além das Aparências Históricas. Rio de Janeiro: Editora Lúmen Júris, 2004.

GOMES, Luis Flávio. Interceptação Telefônica. São Paulo: Revista dos Tribunais, 2007.

LIMBERGER, Têmis. Da evolução do direito a ser deixado em paz à proteção dos dados pessoais. Novos Estudos Jurídicos, v. 14, n. 2, p. 27-53, $2^{\circ}$ Quadrimestre 2009.

LEONARDI, Marcel. Tutela e privacidade na Internet. São Paulo: Saraiva, 2011. Disponível em: <http://leonardi.adv.br/wp-content/uploads/2012/01/mltpi.pdf>. Acesso em: 8 fev. 2018.

Revista de Direito Penal, Processo Penal e Constituição | e-ISSN: 2526-0200 | Porto Alegre | v. 4 | n. 2 | p.

$60-80 \mid$ Jul/Dez. 2018 
LOPES Jr., Aury. Fundamentos do processo penal: introdução crítica. São Paulo: Saraiva, 2016.

LOPES Jr., Aury. Direito Processual Penal. 11. ed. São Paulo: Saraiva, 2014.

MASSON, Cleber. Direito penal esquematizado: parte geral. 6. ed. rio de Janeiro: Forense; São Paulo: Método, 2012.

MENDES, Gilmar Ferreira. BRANCO, Paulo Gustavo Gonet. Curso de Direito Constitucional. 7. ed. São Paulo: Saraiva, 2012.

MORAES, Alexandre de. Direitos Humanos Fundamentais: teoria geral, comentários aos arts. 1 a 5 da Constituição Federativa do Brasil, doutrina e jurisprudência. São Paulo: Atlas, 2013.

MORAES, Alexandre de. Direito Constitucional. 30. ed. São Paulo: Atlas, 2014.

MORI, Michele Keiko. Direito à Intimidade versus Informática. Curitiba: Juruá, 2010.

PRADO, Geraldo. Sistema acusatório: A conformidade constitucional das leis processuais penais. 4. ed. Rio de Janeiro: Lumen Juris, 2006.

QUEIROZ, Paulo de Souza. Direito Penal: introdução crítica. São Paulo: Saraiva, 2001.

RANGEL, Paulo. Breves considerações sobre a Lei 9.296/96. Interceptação telefônica. Disponível em Revista Brasileira de Ciências Criminais. V. 26/1999, p. 143-151. Publicado em abril-junho de 1999.

RODOTÀ, Stefano. A vida na sociedade da vigilância: A privacidade hoje. Rio de Janeiro: Renovar, 2008.

SANCHEZ, Jésus, Mária Silva. A Expansão do Direito Penal: Aspectos das Políticas Criminais nas sociedades Pós-Industriais. 2. ed. São Paulo: Editora Revista dos Tribunais, 2011.

SCHREIBER, Anderson. Direitos da personalidade. São Paulo: Atlas, 2011.

SILVA, José Afonso da. Curso de Direito Constitucional Positivo. 36. ed. São Paulo: Malheiro Editires, 2013.

SILVA, Edson Ferreira da. Direito à Intimidade. 2. ed. São Paulo: Juarez de Oliveira, 2003.

VIEIRA, Sônia Aguiar do Amaral. Inviolabilidade da vida privada e da intimidade pelos meios de comunicação. São Paulo: Juarez de Oliveira, 2002.

WARREN, Samuel; BRANDEIS, Louis D. The right to privacy, in "Harvard Law Review". Cambridge: Harvard Law Review Association, n. 193, 1890. Disponível em: https://www.english.illinois.edu/people/faculty/debaron/582/582\%20readings/right $\% 20$ to $\% 20$ privacy.pdf. Acesso em: jan. 2018. 